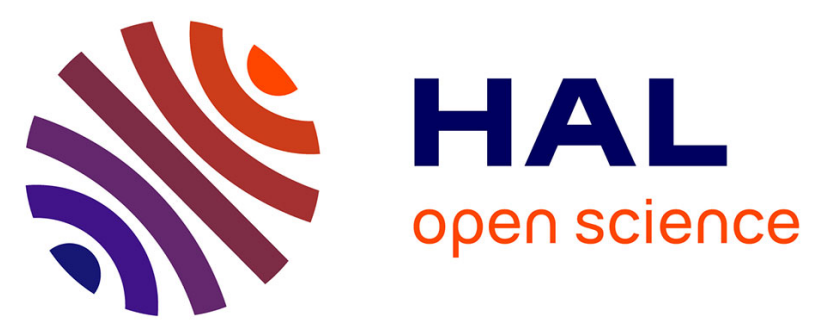

\title{
Versatile Graded-Index Multi-Mode Fiber for High Capacity Single-and Multi-Mode Optical Home Network
}

Aboulaye Fall, Elodie Le Cren, Kevin Lenglé, Catherine Lepers, Yaneck

Gottesman, Monique Thual, Laurent Bramerie, Denis Molin, Pierre

Sansonetti, Dennis van Ras, et al.

\section{To cite this version:}

Aboulaye Fall, Elodie Le Cren, Kevin Lenglé, Catherine Lepers, Yaneck Gottesman, et al.. Versatile Graded-Index Multi-Mode Fiber for High Capacity Single-and Multi-Mode Optical Home Network. 40th European Conference on Optical Communications (ECOC 2014), Sep 2014, Cannes, France. 10.1109/ECOC.2014.6964026 . hal-01080239

\section{HAL Id: hal-01080239 https://hal.science/hal-01080239}

Submitted on 4 Nov 2014

HAL is a multi-disciplinary open access archive for the deposit and dissemination of scientific research documents, whether they are published or not. The documents may come from teaching and research institutions in France or abroad, or from public or private research centers.
L'archive ouverte pluridisciplinaire HAL, est destinée au dépôt et à la diffusion de documents scientifiques de niveau recherche, publiés ou non, émanant des établissements d'enseignement et de recherche français ou étrangers, des laboratoires publics ou privés. 


\title{
Versatile Graded-Index Multi-Mode Fiber for High Capacity Single- and Multi-Mode Optical Home Network
}

\author{
Aboulaye Fall ${ }^{(1)}$, Elodie Le Cren ${ }^{(2)}$, Kevin Lengle ${ }^{(2)}$, Catherine Lepers ${ }^{(1)}$, Yaneck Gottesman ${ }^{(1)}$, \\ Monique Thual $^{(2)}$, Laurent Bramerie ${ }^{(2)}$, Denis Molin ${ }^{(3)}$, Pierre Sansonetti ${ }^{(3)}$, Dennis Van Ras ${ }^{(3)}$, \\ Michel Gadonna ${ }^{(2)}$, Charles Populaire ${ }^{(4)}$, Georges Martin ${ }^{(4)}$, Laurent Valencia ${ }^{(4)}$, Philippe Guignard ${ }^{(5)}$ \\ (1) Institut Mines-Telecom/Telecom SudParis, CNRS UMR 5157 SAMOVAR, Evry, France, \\ abdoulaye.fall@telecom-sudparis.eu \\ (2) Université européenne de Bretagne, CNRS UMR 6082 Foton, Lannion, France \\ (3) Prysmian Group, Haisnes, France \\ (4) Radiall, Voreppe, France \\ (5) Orange Labs, Lannion, France
}

\begin{abstract}
A$ graded-index multi-mode fiber has been optimized to sustain a single excited mode when coupled with a standard single-mode fiber at 1310/1550nm while offering large effective modal bandwidth at 850nm under VCSEL excitations. Modeling and experimental results are presented.
\end{abstract}

\section{Introduction}

Several major evolutions will contribute to a drastic increase of the bit rate required in the Home Network in a near future. Continuously growing bit rate in the access networks with FTTH deployments will soon boost the bit rate demand up to $10 \mathrm{Gbit} / \mathrm{s}$. Other technologies are also widely used to deliver contents, as terrestrial and satellite television. There is a real interest to transport these latter signals in the home in their native radiofrequency format, to ensure a total compatibility with the customer's devices as TV sets or satellite demodulators.

A unique home network able to carry all these signals in their different formats is of high interest, and silica optical fiber technology appears to be the only media providing the required capacity to support the various network systems generation ${ }^{1}$.

We report in this paper on the design, realization and characterization of a home network optical fiber (HNOF) able to be used like a multi-mode fiber (MMF) when using 850nm multi-mode sources, and ensure singlemode propagation when using single-mode sources operating at $1310 \mathrm{~nm}$ or $1550 \mathrm{~nm}$. This solution allows supporting cost effective multimode systems as well as single-mode systems that would arise in the longer term due to bit rate increase and need of more flexibility ${ }^{1}$. This potential for further evolution is particularly important for a medium which will be installed in the walls of the house for decades.

\section{Fiber Design}

Single-mode and multi-mode transceivers, operating at $1310 / 1550 \mathrm{~nm}$ and $850 \mathrm{~nm}$, are respectively ended with standard single-mode fiber (SMF) and standard 50 $\mu \mathrm{m}$ multi-mode fiber (MMF) pigtails. The HNOF is thus excited by SMF or MMF. After propagation through the
HNOF, the excited optical waves are coupled into SMF or MMF pigtails of the receivers.

The compatibility with multi-mode terminations constraints HNOF to be highly multi-mode at $850 \mathrm{~nm}$ like $\mathrm{OM} 3 / 4$ multi-mode fibers in order to be used with high speed Vertical Cavity Surface Emitting Lasers (VCSEL), typically used at this operating wavelength. As a consequence, HNOF is also highly multi-mode at 1310 \& 1550nm. The Effective Modal Bandwidth (EMB) requirements of $500 \mathrm{MHz} . \mathrm{km}$ at $850 \mathrm{~nm}$ have been calculated with the IEEE Spreadsheet model $^{2}$ to support $10 \mathrm{~Gb} / \mathrm{s}$ error-free transmission at $850 \mathrm{~nm}$ over $100 \mathrm{~m}$ (2000MHz.km is required to equal the system performance of OM3 fibers). Therefore, a graded-index profile is recommended.

Single-mode transmissions at high bit rate $(\geq$ $10 \mathrm{~Gb} / \mathrm{s}$ ) over MMF is limited by the modal dispersion, that can be efficiently, and passively, mitigated by using the mode-matched center launch technique ${ }^{3}$. In that case, only the fundamental mode is excited in the MMF. It can be achieved using a tapered fiber between SMF pigtail and $\mathrm{HNOF}^{3}$, or by adapting the refractive index profile of HNOF in order to match the fundamental mode field diameter (FMFD) to that

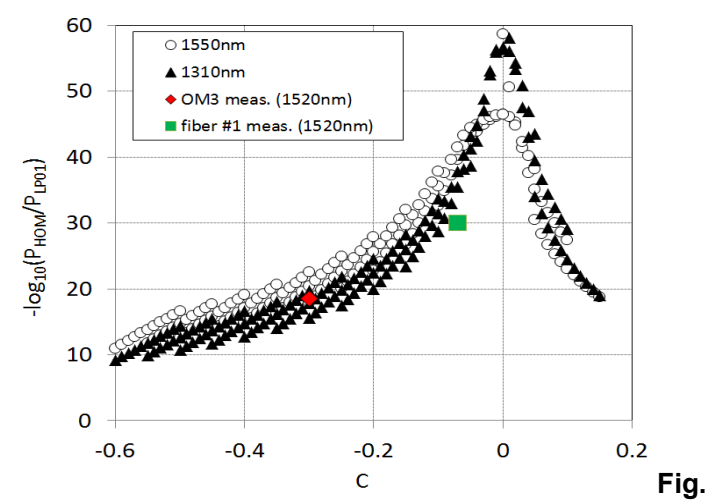

1: HOM optical power over fundamental mode optical power in HNOF excited by a SMF 
of $\mathrm{SMF}^{4}$. For sake of cost efficiency and simplicity, we have chosen the matching option. Instead of using a multi-mode profile with a step index at the core center not compatible with the above mentioned EMB, we tune the gradedindex core diameter (CD) and the numerical aperture (NA) of the fiber to minimize the higher order mode (HOM) excitation. The coupled power ratio between HOM and fundamental mode (LP01) has been simulated for CD between $20 \mu \mathrm{m}$ and $80 \mu \mathrm{m}$ and NA between 0.2 and 0.4 using overlap integral techniques ${ }^{5}$ (Fig. 1). This ratio appears to be correlated to:

$$
C(C D, N A)=-0.01 \cdot C D+N A
$$

with $C D$ in $\mu \mathrm{m}$ at both 1310 \& $1550 \mathrm{~nm}$. $\mathrm{CD}=40 \mu \mathrm{m}$ and $\mathrm{NA}=0.35$ is a good tradeoff between connection losses in multi-mode propagation at $850 \mathrm{~nm}$ and fundamental mode matching in single-mode propagation at $1310 / 1550 \mathrm{~nm}$. Min EMB beyond $500 \mathrm{MHz} . \mathrm{km}$ is achievable despites the large NA with wellknown alpha shaped profiles ${ }^{6}$.

\section{Fiber Characterization}

We have characterized three HNOF samples realized with versatile PCVD process. They exhibit C-parameters between -0.07 and -0.05 . To achieve large NA, the cladding has been down-doped. Refractive index profiles are reported in Fig. 2. Min EMB has been calculated from the Differential Mode Delay measurements using standardized weight functions rescaled to $\mathrm{CD}=40 \mu \mathrm{m}^{7}$. At $850 \mathrm{~nm}$, min EMB of $250 \mathrm{MHz} . \mathrm{km}, 660 \mathrm{MHz} . \mathrm{km}$ and $745 \mathrm{MHz} . \mathrm{km}$ have been obtained for fiber\#1, fiber\#2 and fiber\#3 respectively. It means that higher data bit rate will be obtained with fiber\#2 and \#3 at $850 \mathrm{~nm}$. Fiber attenuation is dominated by Rayleigh scattering, and does not exceed 1.90, 0.38 \& $0.23 \mathrm{~dB} / \mathrm{km}$ at $850 \mathrm{~nm}, 1310 \mathrm{~nm}$ \& $1550 \mathrm{~nm}$. At $1550 \mathrm{~nm}$, HNOF bending losses are less than $1 \mathrm{~dB}$ measured on 20 turns with a bending radius $R=5 \mathrm{~mm}(0.05 \mathrm{~dB} /$ turn compared to $0.15 \mathrm{~dB}$ /turn for G.657.B3 fiber).

\section{Single-mode Propagation Characterization}

Single-mode propagation of fiber\#1 $(100 \mathrm{~m})$ excited by a single-mode pigtail is characterized with OFDR $^{8,9}$ and scan mode ${ }^{10}$ techniques at $1310 \mathrm{~nm}$ and $1550 \mathrm{~nm}$. An OM3 fiber is characterized with the same techniques as the fiber reference.

For OFDR measurements, a time-frequency analysis has been developed. It consists in representing the different interferograms recorded by varying the central wavelength of the OFDR probe (Fig. 3) with a controlled temporal resolution. This permits to measure the temporal responses of the fiber, which depends on the different modes actually excited, over a

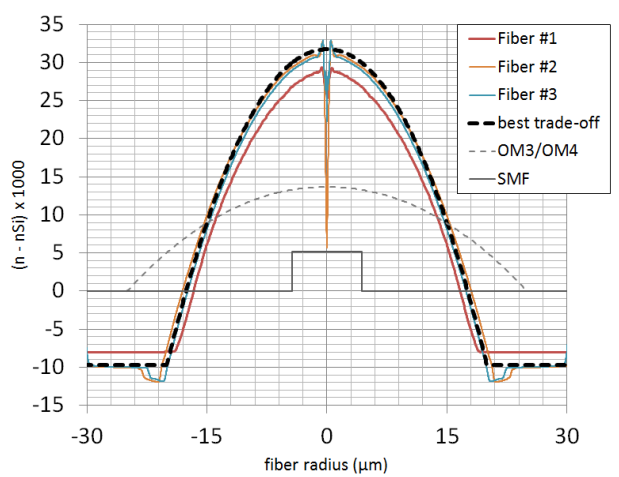

Fig. 2: Refractive index profile of the realized fiber \#1, fiber \#2 and fiber \#3 in comparison with target profile
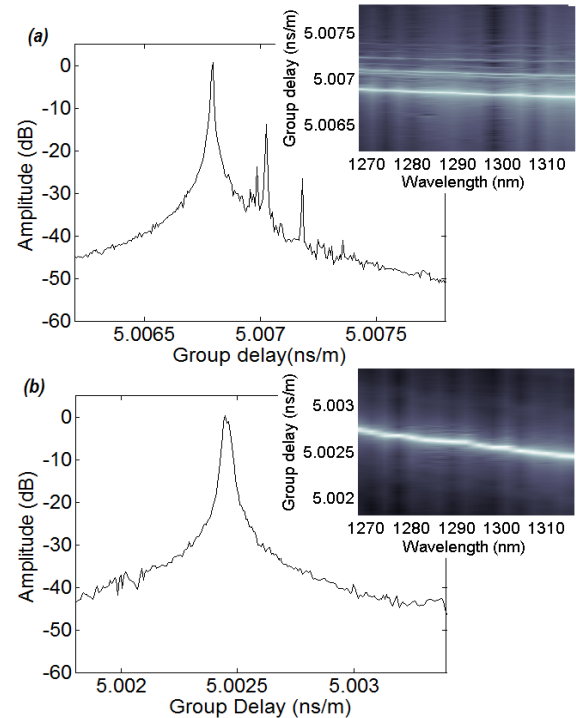

Fig. 3: OFDR reflectogram at $1310 \mathrm{~nm}$ and group delay dispersion curve for (a) OM3 fiber (b) HNOF

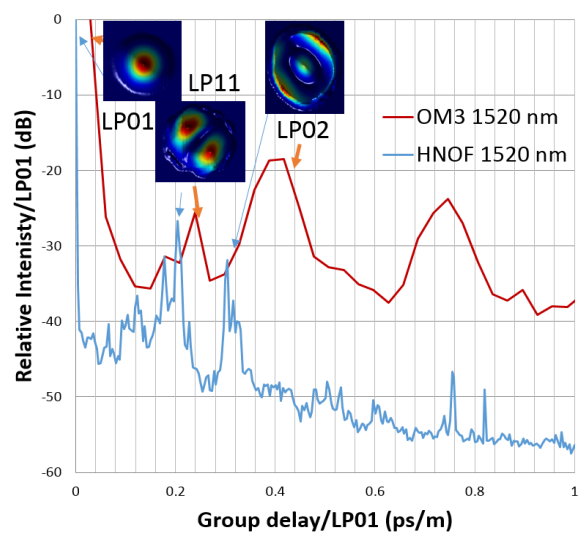

Fig. 4: Relative intensity of higher order modes of HNOF and OM3 fiber versus group delay difference referred to fundamental mode LP01. Associated transverse intensity profile of higher order modes LP11 and LP02

wide spectrum. The diagrams obtained with $2.3 \mathrm{fs} / \mathrm{m}$ resolution, reported in the insets of Fig. 3 , show bright lines that give the fiber group delays of the excited modes as a function of the wavelength. The three lines seen with the OM3 fiber correspond to three excited mode groups, 
while a single line is observed with the HNOF response, indicating that either one single mode is excited or all excited mode groups exhibit close group velocities.

This behavior is confirmed by the scan mode $^{10}$ measurements (Fig. 4) performed at $1520 \mathrm{~nm}$ with $3.9 \mathrm{fs} / \mathrm{m}$ resolution (HNOF) and $30 \mathrm{fs} / \mathrm{m}$ (OM3) that allows to identify the excited spatial modes. The measured coupled power ratio between HOM and the fundamental mode is $-30 \mathrm{~dB}$ with $\mathrm{HNOF}$ and $-18.6 \mathrm{~dB}$ with $\mathrm{OM} 3$ fiber in agreement with modeling (cf. Fig. 1). The LP01 mode field diameters (MFD) calculated from the scan mode measurements confirm that that of fiber $\# 1$ is closer (4\% less than SMF MFD) to that of the SSMF, than that of the OM3 fiber ( $15 \%$ more than SMF MFD).

Additional experimental analysis has permitted to check that bending does not affect single-mode propagation.

\section{System Assessment}

System assessment is performed on $100 \mathrm{~m}$ fiber length (fiber \#1-3 and bend insensitive OM3) at $1550 \mathrm{~nm}$ in single-mode regime. The signal issued from a small form-factor pluggable (SFP) chirped managed laser driven by a $2^{31}-1$ pseudo random binary sequence (PRBS) at $10 \mathrm{~Gb} / \mathrm{s}$. Bit error rate (BER) measurements are performed as a function of the receiver input power (Fig. 5). Error free propagation is observed for all fibers and power penalty between $0 \mathrm{~dB}$ (fiber\#2) and $0.3 \mathrm{~dB}$ (fiber\#1) are measured at $\mathrm{BER}=10^{-9}$ compared to the back to back configuration (reference). Under bending constraints (10 turns, $\quad R=1 \mathrm{~cm}$ ), negligible impact on performance has been measured on fibers \#1 and \#2 whereas $0.4 \mathrm{~dB}$ additional penalty are observed for fiber \#3 and OM3. Similar measurements have been performed in multimode transmission with a $10 \mathrm{~Gb} / \mathrm{s}$ VCSEL SFP at $850 \mathrm{~nm}$ without any error for fibers \#2 and \#3, with a power penalty at $10^{-9}$ respectively of $2.25 \mathrm{~dB}$ and $2.75 \mathrm{~dB}$. No impact is observed under bending constraints. Note that fibre \#1 was assessed only at $7 \mathrm{~Gb} / \mathrm{s}$ in multi mode regime due to the its lower min EMB. In our lab, no modal noise power penalties have been
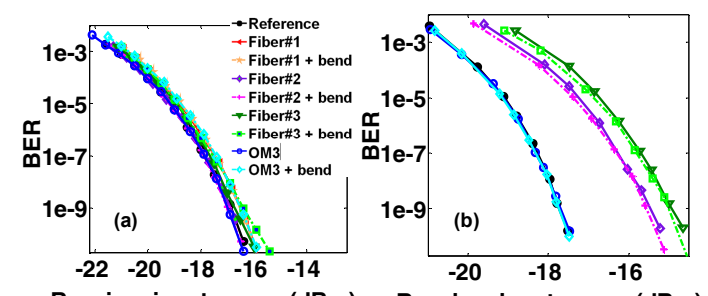

Receiver input power $(\mathrm{dBm}) \quad$ Receiver input power $(\mathrm{dBm})$

Fig. 5: BER measurements with $10 \mathrm{~Gb} / \mathrm{s}$ NRZ signal on $100 \mathrm{~m}$ HNOF fibers and impact of bending constraints ( $R=1 \mathrm{~cm}, 10$ turns) : (a) single-mode, (b) multi-mode observed at $1550 \mathrm{~nm}$ with the OM3 fiber despites the excitation of several modes as previously explained. This may be different in house and would have to be re-assessed in this environment since modal noise is expected to be sensitive to temperature fluctuations and mechanical stress that are generally not controlled at home.

\section{Conclusions}

We have demonstrated the feasibility of a versatile graded-Index multi-mode fiber for high capacity single and multi-mode optical home network. Among its main advantages, it can be either used with single-mode pigtailed transceivers at $1310 / 1550 \mathrm{~nm}$ or multi-mode pigtailed transceivers at $850 \mathrm{~nm}$. To obtain such a result, a graded-index multi-mode fiber has been optimized so that only the fundamental mode is excited when coupled with a standard single-mode fiber at $1310 / 1550 \mathrm{~nm}$ while offering large effective modal bandwidth at $850 \mathrm{~nm}$ under VCSEL excitations. $10 \mathrm{~Gb} / \mathrm{s}$ multi-mode and single-mode error-free transmissions over $100 \mathrm{~m}$ have been demonstrated.

\section{Acknowledgements}

This work is funded by the FUI12 RLDO project.

\section{References}

[1] Ph. Guignard et al., "Multiformat Home Networks using silica fibers", ECOC 2012, Mo1G5.

[2] http://grouper.ieee.org/groups/802/3/ae/public/adhoc/seri al_pmd/documents/10GEPBud3_1_16a.xls

[3] D. H. Sim et al., "High-Speed Multi-mode Fiber Transmission by Using Mode-Field Matched CenterLaunching Technique," J. Lightwave Technol., Vol. 27, No. 8 (2009).

[4] H. Tonobe et al., "Dual-Mode Fiber (DMF) capable of single- and multi-mode transmission," Proc. Of ECOC, 2007.

[5] A. Gholami et al., "Physical Modeling of $10 \mathrm{GbE}$ Optical Communication Systems" J. Lightwave Technol. 29, 115-123 (2011).

[6] R. E. Freund et al., "High-Speed Transmission in Multimode Fibers" J. Lightwave Technol. 28, 569-586 (2010).

[7] Differential Mode Delay Measurement of Multi-mode Fiber in the Time Domain, TIA Fiber Optic Test Procedure (FOTP) 220, January 1, 2003.

[8] B. J. Soller et al., "High resolution optical frequency domain reflectometry for characterization of components and assemblies," Optics Express13(2), 2005.

[9] B. Robillart et al., "Spectral and Temporal Phase Measurement by Optical Frequency-Domain Reflectometry," Proc. of SPIE Vol. 8961 , 896134 (2014)

[10]D. M. Nguyen et al., "Modal Decomposition Technique for Multi-mode Fibers," Applied Optics, Vol. 51 Issue 4, pp.450-456 (2012) 